\title{
Possibilidades de diferentes instrumentos avaliativos utilizados na disciplina de Matemática Financeira: uma disciplina, múltiplos desafios
}

Barbara Oliveira de Morais

\section{Resumo}

O presente relato é o resultado da experiência em sala de aula cuja atuação ocorreu no ano de 2016 em uma Fundação Pública no Rio de Janeiro. A temática das aulas se referiu ao conteúdo de Matemática financeira em duas turmas do curso de Formação Inicial e Continuada das unidades Central do Brasil e Complexo do Alemão. Os objetivos das aulas eram de preparar os alunos para lidarem com questões do cotidiano relacionando tais conhecimentos ao tema de Educação financeira com conhecimentos que auxiliarão na prática profissional dos que pretendiam atuar na área financeira. As experiências em cada unidade exigiram atividades diferenciadas, adaptadas ao cenário de cada gestão da unidade e da realidade dos alunos. As principais dificuldades relacionaram-se ao método de avaliação em que apenas na unidade da Central pode-se atribuir maior peso na participação dos alunos com as dinâmicas propostas. $\mathrm{O}$ uso de jogos, filmes e atividades que promoveram a reflexão e aproximação entre docentes, discentes e familiares foi o ingrediente que permitiu a conexão entre as atividades propostas com as habilidades e conhecimento dos alunos. Considerando que cada experiência em sala de aula é única, mas que os desafios e as barreiras diárias podem ocorrer em diferentes modalidades de ensino. Propôs-se com esse relato o estímulo para a adoção de dinâmicas diferenciadas para o ensino-aprendizagem em sala de aula.

Palavras-chave: Educação financeira, Uso de jogos e Ensino de matemática. 


\section{Introdução}

Este texto é a exposição de minha vivência como professora de um curso profissionalizante em uma Fundação Pública no Rio de Janeiro. Durante a formação de Auxiliares administrativos no ano de 2016, em duas unidades da instituição, localizadas na Central do Brasil e no Complexo do Alemão, áreas carentes do Estado. Foi marcante a experiência aqui relatada, devido aos desafios enfrentados na disciplina de matemática financeira.

As aulas ocorreram no ano de 2016, em duas turmas do curso de Formação Inicial e Continuada, em que através de uma parceria entre o Estado e a Secretaria de Trabalho e Renda do Rio de Janeiro foram viabilizados diversos cursos profissionalizantes para Jovens e Adultos.

Esse relato pretende apresentar brevemente o percurso enfrentado pela autora frente às dificuldades dos alunos do curso profissionalizante de Auxiliar Administrativo, visto que, durante as avaliações foram necessárias readequações dos conteúdos das aulas para que novos métodos, técnicas e estratégias de ensino fossem estabelecidos para contemplar as relações entre os conhecimentos descritos na ementa de conteúdos, e as habilidades e atitudes esperadas dos alunos no desenvolvimento das atividades.

\section{Sobre a Fundação Pública}

Anualmente são abertos editais visando à contratação de temporários para suprir a necessidade de seleção de profissionais para estarem em sala de aula, atuando como professores e instrutores nos cursos de formação inicial e continuada. No ano de 2015, me deparei com a oportunidade de atuar em um desses cursos, devido minha formação na área de Recursos Humanos, Contabilidade e na época em Administração Pública. Além disto, pensei na importância de levar aos alunos a minha experiência profissional de mais de dez anos no mercado de trabalho e também teórica, adquirida nas formações citadas.

Apesar da motivação para levar o conhecimento a esses alunos, não fui selecionada na primeira chamada do processo seletivo. Mas era o destino estar com essas turmas, uma vez que alguns meses depois fui chamada para assumir a vaga do profissional anterior. Devido minha insegurança por atuar pela primeira vez em um curso para Jovens e Adultos, compreendia a responsabilidade de ser ferramenta de mudança na vida desses alunos. O público alvo do curso eram, em sua maioria, jovens na faixa de 19 a 24 anos, desempregados, com o Ensino Médio completo e moradores de comunidades do Rio de Janeiro.

Em mim, havia a esperança de levar a esses alunos uma esperança, de novos tempos, em que eles poderiam escrever uma nova história frente à realidade tão dura de suas vidas. Foi com essa expectativa que cheguei à sala de aula, confiante que tudo daria certo. 


\section{A frustração das primeiras semanas}

Embora a motivação estivesse em alta, as primeiras semanas foram muito difíceis. Os alunos haviam se conectado com o professor anterior e me receberam desconfiados, chateados pelo fato de eu estar ali no lugar de quem eles já conheciam. Acreditaram que eu havia tomado seu lugar e as primeiras aulas não foram as melhores, mas serviram como experiência e reflexão para que eu pudesse rever todo o planejamento feito.

Na unidade da Central do Brasil a turma era muito menor, composta de 14 alunos sendo a maioria do sexo feminino. Devido as alunas serem mais maduras, com experiências anteriores no mercado de trabalho, mas que desejavam recolocação em uma nova área a receptividade foi diferente em relação a outra unidade. As atividades com essa turma eram realizadas diariamente no turno da manhã entre 7:30 às 12 horas. A partir da segunda semana eu já estava mais à vontade com a turma e por ter menos alunos que a outra unidade foi mais fácil me aproximar e conquistá-los.

Já na turma do Complexo do Alemão, a sala era mais cheia, com 42 alunos, a maioria de jovens sem experiência profissional e com a esperança de a partir do curso conseguirem uma vaga no mercado de trabalho. Por serem jovens e eu na época ter 27 anos, estava próxima da idade de muitos deles, mas em um primeiro momento esse não foi o ponto que serviu para nos aproximarmos, ao contrário.

Quando eu percebi que precisava conhecer a trajetória de vida dos meus alunos, saber quem eles eram, de onde vinham, suas expectativas, ambiente familiar, as razões de escolherem aquele curso, foi aí que tudo mudou: eu lhes dei meus ouvidos, meu olhar e importância as suas falas. Um novo ciclo se iniciava.

\section{A experiência na Unidade Central do Brasil}

Como exposto anteriormente, as primeiras semanas não reservaram as melhores sensações. As aulas ocorriam diariamente, com intervalo de 30 minutos para o lanche. $\mathrm{Na}$ unidade Central do Brasil, a turma era composta por 14 alunos, mas no início nem 5 alunos frequentavam as aulas. Inquieta pela ausência dos alunos comecei a questionar as razões das faltas, já que até a saída do professor anterior essas eram pontuais.

As desculpas iniciais se referiam ao dia de violência na comunidade, depois era pelo cansaço, insatisfação com a troca de professores, ausência de material e do cartão de passagem. Lá no fundo eu pensava sobre como a minha chegada tinha participação nessas faltas. Foi preciso então conquistar esses alunos, mas para isso eu precisava da ajuda da coordenação pedagógica para trazê-los novamente para a sala de aula.

Depois de levar para coordenação pedagógica as faltas frequentes, a terceira semana trouxe os alunos de volta para a sala e a partir daí caberia a mim mantê-los motivados e atentos. 
Durante as aulas da terceira semana formulei atividades para conhecer a trajetória de vida dos alunos. Uma das propostas visava à apresentação de si mesmo para a turma, que a essa altura estava organizada em uma roda de conversa para que eu e eles nos aproximássemos.

Durante as atividades os alunos puderam se (re)conhecer, expuseram de onde vinham, as razões para estarem ali e suas expectativas com a nova formação. Mediante as falas pude conhecer como era constituído o ambiente familiar e descobri que algumas alunas eram mães, estavam ali querendo um futuro melhor para seus filhos, visto que recebiam benefícios sociais e estavam desempregadas.

A partir dos relatos eu pude compreender o quanto a minha chegada envolvia desconfortos, pois cada um para estar ali presente e se manter motivado precisava de muito mais do que aulas, precisava da minha motivação também, de alguém que os enxergasse além de alunos, mas como pessoas.

\section{A experiência na Unidade Complexo do Alemão}

As aulas na unidade do Alemão ocorriam diariamente na parte da tarde no horário das 13 às 17:30h. Todos os dias por atuar em duas unidades em locais diferentes eu corria entre uma unidade e outra, e por essa razão abria a sala de aula para preparar a rotina de aprendizagem.

No início, assim como na Central a ausência dos alunos em sala era devastador. Eu me questionava sobre como atuar ali já que a turma era bem maior e com um perfil mais jovem do que a outra unidade. A experiência em cada unidade me levou a formular uma escolha de representante de turma, para que eu tivesse um porta-voz das atividades e me conectasse melhor aos alunos.

Nessa unidade os desafios eram diários, tinha dia com 6 alunos, no outro com 10 e assim como na unidade da Central foi preciso me aproximar do pedagógico para trazer esses alunos para sala. Na época, a Secretaria de Trabalho e Renda e a referida Fundação estavam com alguns problemas no cartão de passagem e a maioria dos alunos alegavam que as ausências se davam devido à falta das passagens. Esse foi o gatilho para eu me aproximar dos alunos: brigar pelos direitos com eles seria a primeira iniciativa de demonstrar que eu me importava com eles. E assim foi feito. Depois de duas semanas, as coisas estavam se resolvendo e eu consegui conquistar uma parte da turma pelo simples fato de me mostrar estar ao lado deles.

Embora o cenário já fosse melhor do que a recepção inicial alguns alunos continuavam ausentes e embora o setor pedagógico atuasse intervindo na comunicação para sondagem das ausências, não me sentia feliz com aquele resultado. Sem me dar por vencida, iniciei atividades para envolver os alunos, fazendo-os contemplar a experiência da aprendizagem que eles 
estavam recebendo e da importância dos colegas que estavam ausentes da sala e que não estavam sendo contemplados. Com mais uns dias a turma foi sendo sensibilizada e os alunos começaram de fato a frequentar as aulas.

\section{Sobre as aulas de Matemática Financeira}

Apesar de todos os desafios nas primeiras semanas em ambas as unidades, eu estava me sentindo confiante. Era como se todas as turbulências me mostrassem um pouco da realidade que vários outros professores silenciosamente se deparam diariamente e que ainda assim sem experiências e com altas expectativas, tivessem que contornar todos esses fatos e "tocar o barco". E por que eu não conseguiria também?

Quando tudo começou a caminhar eu pude efetivamente passar o conteúdo e realizar as avaliações, porém, essa foi uma nova etapa de muitos desafios. Seguindo o cronograma estipulado pela Fundação pública, fui levando para sala de aula diversas questões da matéria e a cada exposição dos temas sentia os alunos espantados, inseguros, preocupados em ter que algum momento demonstrar conhecimento sobre o que eu estava passando ali.

Naquele estágio, eu já conseguia "sentir" na expressão dos alunos a dificuldade e vontade de conseguir compreender o conteúdo. Em uma sexta-feira, alguns alunos do Alemão chegaram para mim e começaram a falar sobre seus sonhos, um deles queria muito ser professor de matemática e ele de fato parecia entender e gostar bastante das aulas. Foi aí que ele me auxiliou a pensar em uma estratégia para a aprendizagem da turma: ele disse para mim que as atividades em grupo estimulavam a cooperação e que se tivesse como ensinar através de um jogo, colocando alguma premiação no final "a galera iria se amarrar”.

Passei a viagem inteira na condução para casa pensando em como adaptar as aulas de matemática financeira para as duas turmas, pois queria levar para todos os meus alunos as mesmas experiências. Ainda que cada aluno reagisse de uma forma, tentei refletir sobre aquela fala do trabalho em grupo e comecei a elaborar a estratégia para na próxima semana já colocar em prática as atividades.

\section{Elaboração das Novas aulas de Matemática Financeira}

No final de semana de setembro, com a mente tomada pela necessidade de trazer a experiência da disciplina para a sala de aula com algum tipo de atividade lúdica, comecei a buscar no Google e no Youtube por aulas de matemática que buscassem a mesma proposta que a minha: trazer a realidade dos alunos para o conteúdo em sala.

Após algumas pesquisas, encontrei um artigo científico elaborado por Mendes, Bianchesi e Cardoso (2015) que quinzenalmente implementaram em uma escola de Ensino Médio o projeto Matemática e suas Aplicações. Nesse projeto os autores se depararam com 
uma das realidades que eu também tive: os alunos tinham dificuldades em estabelecer conexão entre o conteúdo e o cotidiano e a partir de então, adaptaram o jogo "Vida Financeira", criado pelo Banco Santander para as atividades práticas em sala de aula.

Devido a experiência relatada no artigo "Jogando com a matemática financeira" resolvi seguir os passos dos autores e adaptei o jogo para realidade dos meus alunos. Um dos desafios foi pensar em cada cenário, pois cada unidade tinha uma quantidade diferente de alunos e seus perfis eram bem diferentes. Foi aí então que pensei em um projeto diferente para cada unidade e que será relatado com maior profundidade a partir de agora.

\section{O projeto de negócio da Unidade Central do Brasil}

No trabalho de Mendes, Bianchesi e Cardoso (2015) os autores relataram que os alunos apresentavam algumas dificuldades ao calcularem os juros, principalmente os juros compostos e inflação. Nas minhas turmas poucos alunos conseguiam calcular sem nenhuma dúvida atividades relacionadas a esse tema. A partir da ideia do "Jogando com a matemática financeira" conversei com os professores dos outros cursos FIC para que juntos pudéssemos auxiliar nossos alunos.

Na unidade Central do Brasil os cursos FIC contemplavam a formação em Culinária, Turismo, Recepção, Empreendedorismo, Idiomas, Estética e os que eu atuava. Como a maioria dos alunos atuavam fazendo "bicos" e empreendendo aqui e ali, conversei com os professores para envolvermos os alunos em atividades de Educação Financeira, trazendo a experiência de vida desses alunos para o contexto da Matemática Financeira.

A atividade foi realizada em dez grupos mistos, contendo alunos de cursos diferentes para que além da interação pudessem trabalhar em grupo através de uma atividade interdisciplinar. Como primeira atividade os alunos deveriam montar um negócio, descrevendo o público-alvo, atuação, nome, recursos iniciais para investimentos, quantidade de funcionários e outras características básicas desse negócio.

Como o negócio precisaria de um investimento inicial, os professores seriam as linhas de crédito. Cada professor ficou responsável por ser uma linha de crédito diferente. Um era o cheque especial, o outro o cartão de crédito, eu era o cheque, a outra professora era a nota promissória e por fim cada linha tinha um benefício na concessão do crédito com seus respectivos juros e formas de pagamento.

Para trazer os alunos para o jogo e também para as atividades, formulei simulações que fizessem os alunos contrair pelo menos uma linha de crédito por vez e assim os alunos poderiam fazer compras simulando os cálculos que estavam previstos no contexto da disciplina. Cada aula foi ficando tão interessante que os alunos começaram a trazer as próprias simulações para a aula como negociação de crédito para parcelamento de débitos e também 
para compra de mercadoria para vendas como comerciantes ambulantes.

Naquelas semanas, nossa aproximação foi ficando ainda mais fortificada e a compreensão das atividades saiu de uma única turma e sala e expandiu para outros cursos da unidade. Devido a sugestão da direção e o engajamento dos alunos montamos a semana de Educação Financeira que foi o ponto alto da unidade naquele período.

Passada a dinâmica deste jogo, percebi que a satisfação dos alunos com as aulas estava muito boa e procurei deixar as atividades mais atrativas e propus para a direção que as avaliações da minha disciplina passassem a ser 70\% em formato de jogos e os outros $30 \% \mathrm{em}$ trabalho e prova. O desafio agora era o de selecionar novos jogos tão interessantes quanto o primeiro e de ter além da aceitação a aprendizagem de fato.

Novos jogos foram selecionados apoiados na dissertação de Mestrado de Jover (2014) que no Jogo investindo na Vida possibilitou que meus alunos pudessem ter contato com seis atividades distintas dentro do mesmo jogo através das cartas de atitudes: consumir, ir ao banco, investir na bolsa de valores, atuar no mercado financeiro, empreender e focar no trabalho.

A experiência com as atividades permitiu que a cada tema teórico eu pudesse trabalhar as atividades práticas via jogos e que os alunos contemplassem até mesmo outra realidade distinta da comunidade em que moravam. Muitos alunos sequer conheciam o funcionamento de uma Bolsa de Valores e passar a eles o filme O Lobo de Wall Street (2013), compartilhando uma tarde com pipoca e conversa sobre o filme foi uma experiência muito marcante, pois a cada dia eu descobria o quão podemos sim avaliar nossos alunos além de uma nota mediante um resultado no papel devido uma fórmula.

\section{O projeto desenvolvido na Unidade Complexo do Alemão}

Como nem tudo são flores tentei levar a mesma atividade para a unidade do Alemão. Por lá, os professores não se interessaram pela dinâmica, alegaram que já tinham muitas atividades para se "ocuparem com mais uma besteira”. Aí eu percebi a dificuldade que a gente enfrenta em formular aulas integradoras, que dialoguem com outras disciplinas: é preciso que ambos os lados queiram se envolver.

Devido a experiência da Central ter estimulado a semana de Educação Financeira, conversei com a direção da unidade do Alemão para levar a atividade ainda que não tivesse a aprovação dos demais professores para atuarem em conjunto comigo. A direção gostou da ideia, mas alegava que avaliar os alunos por atividades assim não era o suficiente para dar notas para os alunos e não era algo "legal" do ponto de vista pedagógico, que era melhor passar só o filme e usar o mural sem os alunos exporem os resultados dos negócios.

Não imaginava que o entrave inicial fosse meus colegas de unidade, acreditava que os 
alunos talvez é que nem gostassem da ideia e atividades. Por não poder executar plenamente as atividades, precisei pensar em como levar os jogos apenas ali para sala de aula. Foi a partir daí que procurei novos autores que tivessem limitações como eu e que pudessem agregar novas experiências para minhas atividades em sala.

Usando a pesquisa de Theodoro (2015) que trouxe sugestões para se trabalhar a educação financeira em sala de aula e fora dela, com os pais de alunos, outros professores ou membros da comunidade em geral, levei para sala sete atividades diferentes adaptadas do exposto por Theodoro (2015) e descritas a seguir.

$\mathrm{Na}$ primeira atividade que visa promover a consciência dos alunos sugeri a eles conversarem com sua família e colocarem em uma folha todas as despesas básicas da casa (água, luz, telefone, compras no mercado, remédios, passagem de ônibus e gastos supérfluos) e as dívidas, visando investigar o consumo de cada família. Além das despesas, eles deveriam descrever em porcentagem quanto era a renda da família. O objetivo dessa atividade era de estimular os alunos a ter educação financeira desde casa. Ao conversarem com seus familiares, os alunos teriam contato com as despesas e receitas da família.

Quando os alunos levaram a atividade para sala formulamos o jogo das linhas de crédito, adaptando um pouco a mesma atividade que fiz na unidade da Central para a realidade da unidade do Alemão. Simulamos os juros de cada modalidade e refletimos sobre o endividamento das famílias e a consciência com os gastos.

O objetivo da atividade foi o de levar o conteúdo da aula para casa, dos alunos com o papel de multiplicadores, com possíveis soluções para redução dos gastos e endividamento. Os alunos ficaram fascinados por poderem formular alternativas que eles pudessem contribuir em suas casas. Sem dúvidas uma das atividades que mais se envolveram desde o início do curso, sendo o pontapé para as demais.

Na segunda atividade, que visou promover a organização solicitei aos alunos que se organizassem em sete grupos com seis alunos para que eles levassem encartes de jornais ou revistas com sugestões de compras como imóveis, automóveis e empréstimo pessoal. Juntos, os alunos de cada grupo formularam a organização da compra de um desses bens com a simulação mediada por mim.

Já a terceira e quarta atividade, que visou promover o orçamento e a pesquisa, sugeri aos alunos que ainda em grupo fizessem a pesquisa em ao menos três supermercados sobre os valores dos itens dos alimentos consumidos na residência deles. O objetivo dessa atividade foi o de planejar os gastos com mercado e o de estímulo a pesquisa de valores. Uma das razões de endividamento se dá pela falta de controle dos gastos das famílias e poder trabalhar com os alunos essas questões permitiu além do trabalho em grupo a observação sobre em que eu gasto 
meu dinheiro, e ainda saber como e quanto está sendo poupado? Essas são questões chaves a todos aqueles que desejam dominar suas finanças.

Na quinta atividade, buscou-se incentivar o controle das finanças pessoais dos alunos e seus familiares. Nessa atividade, foram estimulados que em virtude dos gastos expostos na dinâmica de consciência que os gastos fossem controlados através de um formulário compartilhado com os alunos. Para que eles pudessem exercitar na prática a atividade com seus familiares foram estimulados que um mês depois eles trouxessem para sala de aula os gastos anotados no formulário.

Essa atividade teve uma boa participação, mas nem todos conseguiram anotar todos os valores gastos e se propuseram a tentarem novamente no mês seguinte. Como forma de estimular a participação, os alunos que entregassem a tarefa seriam levados a conhecer alguns pontos turísticos do Rio de Janeiro como o Museu do Amanhã, Centro Cultural Banco do Brasil (CCBB) e Museu de Arte do Rio. Devido aos estímulos, a participação cresceu bastante e se mostrou efetiva no auxílio dos gastos dos alunos e seus familiares.

A sexta e a sétima atividade intitulada meta e investimento foi uma proposta para a festa de fim de ano dos alunos. Definimos os itens que iriam compor a confraternização da turma e fizemos a estimativa dos gastos com esses itens. A partir desse planejamento estipulamos quanto cada um deveria juntar para colaborar com a caixinha da turma. $\mathrm{O}$ valor diário de contribuição por aluno foi de $\mathrm{R} \$ 0,10$ (dez centavos).

Como meta o valor por mês foi de $\mathrm{R} \$ 84$ (oitenta e quatro reais) e por essa razão o valor simbólico de dez centavos seria o suficiente para que de 16/o9/16 até 18/12/16 o dinheiro necessário fosse recolhido e a festa ocorresse. Em dezembro o valor total arrecadado superou a meta estipulada. O previsto de arrecadação era de $\mathrm{R} \$ 300,00$ (trezentos reais) e devido a turma depositar na caixinha mais do que o valor estipulado diariamente, muitas vezes moedas de 25 e 50 centavos, alcançamos em dezembro o total de $\mathrm{R} \$ 674,00$ (seiscentos e setenta e quatro reais). Mais do que o dobro da meta.

Essa atividade foi importante para que os alunos tivessem a percepção sobre previsão de gastos, poupança e investimento em longo prazo. Devido a festa ter ocorrido meses após a previsão de gastos iniciais alguns produtos sofreram alterações e essa também foi uma oportunidade de observar na prática a flutuação de preços e preparo para imprevistos.

As dinâmicas e avaliações a cada atividade prática contribuíram para trazer o ensino da matemática financeira para a realidade dos alunos, sendo perceptível que a satisfação e motivação para a execução dessas atividades contribuíram para que o cenário inicial de ausência em sala, baixa participação e dúvidas quanto aos conteúdos fossem superados. 


\section{O que aprendi nesse percurso}

Refletir sobre essas experiências e colocá-las no papel trazem recordações que me marcaram muito principalmente pelas inúmeras vezes que eu me questionei sobre estar cumprindo o papel que eu me propus: de ser ferramenta de mudança na vida dos meus alunos. Cada turma me marcou tanto que as festas de confraternização, as cartas e lembranças foram registradas por fotos, papéis e recordações que brevemente eu relatei aqui.

A experiência como professora em um curso de Formação Inicial e Continuada (FIC) talvez não seja próximo à experiência do ensino fundamental ou médio de tantos professores, mas acredito que as dificuldades e barreiras impostas e a vontade de rompê-las é inerente a todas as modalidades de ensino.

Por essa razão, ao compartilhar as duas diferentes experiências vivenciadas nas unidades Central do Brasil e Complexo do Alemão, quis trazer à tona a missão de amor que temos enquanto professor: que é a de transformar a experiência dos discentes ao mesmo tempo em que transformamos a nossa para auxiliá-los em seu percurso de aprendizagem, objetivo este que vai ao encontro da ideia da avaliação da aprendizagem defendida por Luckesi (2000), visto que a avaliação inclui, traz para dentro. Enquanto ensinamos aprendemos em conjunto, nos reinventamos, cruzamos barreiras que antes pareciam distantes, mas que aos poucos se tornam tangíveis.

O ato de avaliar para De Freitas Albertino e De Souza (2004) devem auxiliar o educando na construção e reconstrução dos conhecimentos para favorecer o pleno desenvolvimento profissional e consolidar a existência de uma postura mais crítica e inovadora, entretanto, diversas são as barreiras avaliativas que os educadores enfrentarão. No caso da matemática financeira, cada unidade teve a sua particularidade e enquanto a unidade da Central teve sua avaliação com peso maior através dos jogos e dinâmicas, na unidade do Complexo do Alemão eu tive que transformar essas participações em pontos extras, pois não me permitiram dar maior peso para esse tipo de avaliação prática e de trabalho em grupo.

Diante do exposto, tem-se que práticas em sala de aula que promovem a aproximação do conteúdo com a realidade do discente a partir de metodologias ativas de aprendizagem, viabilizam a interação entre os discentes e quebram o paradigma de que apenas as atividades em formato de prova ou teste é que de fato avaliam conhecimento, habilidade e aprendizagem.

\section{Referências}

DE FREITAS ALBERTINO, Fátima Maria; DE SOUZA, Nadia Aparecida. Avaliação da aprendizagem: o portfólio como auxiliar na construção de um profissional reflexivo. Estudos em Avaliação Educacional, n. 29, p. 169-190, 2004. 
JOVER, Renato Schneider Rivero. Matemática financeira no Ensino Médio: um jogo para simulação. 2014.

LUCKESI, Cipriano Carlos. O que é mesmo o ato de avaliar a aprendizagem. Revista Pátio, v. 12, p. 6-11, 2000.

MENDES, Luis Filipe; BIANCHESI, Camila F.; CARDOSO, Andréa. Jogando Com A Matemática Financeira. Proceeding Series of the Brazilian Society of Computational and Applied Mathematics, v. 3, n. 1, 2015.

THEODORO, Flavio Roberto Faciolla. Matemática e Educação Financeira: uma experiência com o ensino médio. Revista de Educação, v. 13, n. 15, 2015.

\section{Biografia Resumida}

Bárbara Oliveira de Morais: Mestranda em Práticas em Desenvolvimento Sustentável pela Universidade Federal Rural do Rio de Janeiro (UFRRJ).

Link do Lattes: http://lattes.cnpq.br/1459514405004604

e-mail: bomorais@gmail.com 